\title{
Educational interventions improved some quality of life outcomes in prostate cancer
}

Lepore SJ, Helgeson VS, Eton DT, et al. Improving quality of life in men with prostate cancer: a randomized controlled trial of group education interventions. Health Psychol 2003;22:443-52.

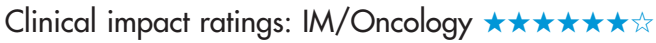

In men with prostate cancer, do educational interventions improve symptoms and quality of life (QOL) outcomes?

METHODS

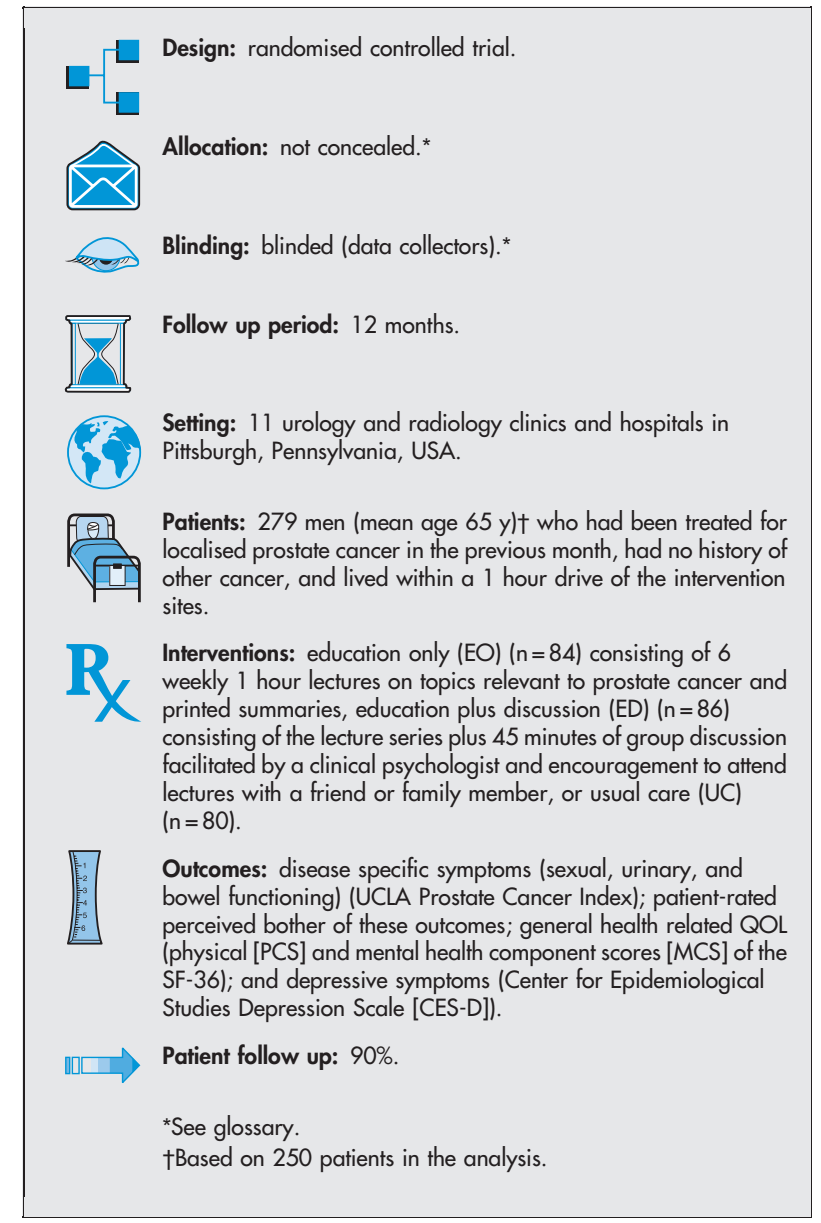

\section{MAIN RESULTS}

Analysis was by intention to treat, although no allowance was made for missing data. Sexual, urinary, and bowel functioning scores improved over time but were not affected by interventions or educational status. Immediately after the intervention, patients in the intervention groups were more knowledgeable about prostate cancer than the UC group, but only those in the ED group increased positive health related behaviours and they indicated less sexual bother (table). An intervention effect was seen for PCS scores in men without a college degree. No effect of the intervention was seen on MCS or CES-D scores, which remained low from baseline (table). More men in the ED group remained stably employed $(93 \%)$ than did men in the EO $(76 \%)$ or UC $(73 \%)$ groups $(\mathrm{p}<0.05)$.

For correspondence: Dr S J Lepore, Columbia University, New York, NY, USA. lepore@tc.columbia.edu

Source of funding: National Institutes of Health.

\section{CONCLUSION}

In men with prostate cancer, educational interventions improved some quality of life outcomes more than usual care.

\section{Commentary}

epore et al report that for some outcomes, the ED intervention was better than EO, particularly in men without a college degree. How- ever, this does not mean that such interventions should be focused on men with lower educational attainment. Like women, men seem to value group participation to compare their experiences and progress with those of others. ${ }^{1}$ Men with lower educational attainment may derive benefit from groups when, as in this study, the groups also include men with higher education attainment. The ED intervention also included separate groups for the patients' partners, and it is likely that this additional factor influenced some outcomes (eg, bother from sexual problems).

No benefits were observed from educational interventions on sexual and urinary functioning. Educational interventions are most likely to lead to improved physical outcomes when the latter can be substantially influenced by health behaviours. This is more likely to occur in illness like diabetes than in prostate cancer.

In this study, men had better initial SF-36 scores than community samples of men, and very low levels of depression. While some studies have reported levels of depression and functioning among men with early prostate cancer similar to those of other hospital outpatients, others have, like this study, reported a low prevalence of depression. ${ }^{2}$ Unfortunately, this study does not provide sufficient detail to exclude the possibility that those included in the study were a selected sample. However, even if this is the case, men like those recruited to the study are probably those most likely to participate in educational or support groups.

$$
\begin{array}{r}
\text { Tom Sensky, PhD, FRCPsych } \\
\text { Imperial College } \\
\text { London, UK }
\end{array}
$$

1 Krizek C, Roberts C, Ragan R, et al. Gender and cancer support group participation. Cancer Pract 1999:7:86-2.

2 Bisson Jl, Chubb HL, Bennett S, et al. The prevalence and predictors of psychological distress in patients with early localized prostate cancer. BJU Int 2002;90:56-61.

Outcomes for men with prostate cancer at 12 months*

\begin{tabular}{lllll}
\hline Outcomes & $\begin{array}{l}\text { Education } \\
\text { only }\end{array}$ & $\begin{array}{l}\text { Education }+ \\
\text { discussion }\end{array}$ & Usual care & $\mathrm{p}$ Values \\
\hline $\begin{array}{l}\text { PCS } \\
\text { (score range }\end{array}$ & 48.3 & 49.4 & 47.4 & $<0.10$ \\
$\begin{array}{l}\text { O-100)t } \\
\text { MCS }\end{array}$ & 53.1 & 54.0 & 53.4 & 0.95 \\
$\begin{array}{l}\text { (score range } \\
\text { 0-100)t }\end{array}$ & & & & \\
$\begin{array}{l}\text { CES-D (score } \\
\text { range 0-3) } \\
\text { Sexual bother } \\
\text { (score range }\end{array}$ & 0.43 & 0.35 & 0.40 & 0.73 \\
$0-100) \dagger$ & & 56.2 & 38.0 & $<0.01$ \\
\hline
\end{tabular}

*Values are means. $\mathrm{PCS}=$ physical health component scores;

MCS = mental health component scores; $C E S-D=$ Center for

Epidemiological Studies Depression Scale.

tHigher scores = better functioning.

$\ddagger$ Higher scores $=$ greater depressive symptoms 